\title{
Communications
}

\section{Design and Development of a Himalayan Studies Information System for India: A Proposed Model}

\begin{abstract}
Anil Singh
The ever-increasing need for information, with its complexity and escalating costs; the enormous growth in publications, and the emergence of subject specialization have compelled librarians to share resources through information networks and systems. This paper describes the necessity of networking among the Himalayan Studies and Research Centers in India, allowing the sharing of information originating from the Himalayan Studies Information System (HIMIS). The paper also discusses in brief the definition of information systems, as well as the objectives and needs of a proposed HIMIS.
\end{abstract}

The recent advancements in the computer, communications, and networking technologies have brought about three paradigm shifts. There is the shift of information resources from print to electronic media, the shift in the role of information providers from passive to proactive, and the shift from manual to automated information delivery. This has presented library and information professionals with a tremendous challenge, that of playing a proactive role not only in their routine activities (acquisition, processing, and dissemination), but also in the actual learning process of their clientele. Library and information professionals have to learn to scan, filter, interpret, analyze, repackage, and deliver information from a variety of sources in ways that are meaningful to their users. ${ }^{1}$

Himalaya, the greatest physical feature of the earth, is not only an integral part of history and heritage, but it has also assumed the form of a social, cultural, and geo-political reality that cannot be ignored or underestimated. This mountain range makes an enormous contribution to our contemporary life, even as it influenced our history and mythology. Furthermore, this influence promises to extend even to the future. ${ }^{2}$

The Himalayas have always remained a source of fascination and inspiration for people from all walks of life, and have been deemed by the peoples of the subcontinent to be the cradle of human civilization. The variety of cultures, terrains, forest physiographies, flora, and fauna of this region has lured the intelligentsia of the world since time immemorial. In recent years, however, the Himalayas have become the focus of attention of scientists and government alike. Efforts are underway for a better understanding of its highly complex environmental and ecological systems, and to bring about an all-around development of the region, which has remained backward throughout the centuries. ${ }^{3}$

There has been a tremendous explosion of data and information in recent years, particularly in the field of Himalayan resources, with an increase in the number of research and development institutions at the national and international level. While most of these research institutions and universities possess excellent libraries and information centers, there is at present no information network by which coordination and sharing of resources could be effected for the mutual benefit of each of the existing libraries. Because there is little access to the right information at the right time, it has become difficult for one single organization to collect the data and information that are required by policy makers, administrators, and research scientists. The other scientific departments of the government of India have already started planning to begin information networking in their respective areas. Some of these projects are completed and others are in the process of implementation. ${ }^{4}$

During the last decades, India has been active in setting up information systems and networks, and considerable progress has been achieved in this area (figure 1). Since most of the information related to the Himalayas is scattered in different research-andstudies centers all over India, there is a need to develop a Himalayan Studies Information System (HIMIS). HIMIS will be a computer-communication network for linking various libraries and information centers of research and development (R\&D) institutions, universities, and nongovernmental organizations (NGOs) working on the Himalayas. The system, therefore, has to take into account the specific information requirements of each development sector so far as its relevance to the Himalayas is concerned.

\section{Defining Information Systems}

The purpose of an information system is to provide accurate and relevant information to users at the right time and at the appropriate level of detail. This will help ensure that the corporate information resource is utilized fully. ${ }^{5}$

Buckingham defines an information system as a

system which assembles, stores,
processes, and delivers informa-
tion relevant to an organization
(or to society), in such a way
that the information is accessible
and useful to those who wish
to use it, including managers,
staff, clients, and citizens. An

Anil Singh (rathoreas@ hotmail.com) is Professional Assistant, Division of Lib-rary, Documentation and Information, National Council of Educational Research and Training, Sri Aurobindo Marg, New Delhi, India. 
information system is a human activity (social) system which may or may not involve the use of computer system.

Harrod's Librarians' Glossary defines information system as an organized procedure for collecting, processing, storing, and retrieving information to satisfy a variety of needs. ${ }^{7}$ According to Bowman, four different components can be identified: (1) A store of useful information that has been accumulated over a period of time; (2) a series of techniques used for adding material to and retrieving information from the store upon demand; (3) a group of people who operate the system and are responsible for selecting information to be added, answering questions, organizing the store, and for implementing and modifying the techniques for both storage and retrieval; and (4) the user. The ultimate test of any such system is the degree of satisfaction it gives the user who has specific information needs. ${ }^{8}$

\section{Setting Up HIMIS}

The volume of Himalayan information plus the number of users and their various requirements have created a situation where it is almost impossible for any single library to provide information services singlehandedly. It is only through a network of all these information centers that some viable control of Himalayan information is feasible, not only at a local level, but also at the national and international level, to ensure effective use of information resources to the best advantage at a minimum cost. These days, information is being regarded as a national resource, and this awareness has led to computerbased information services such as indexing and abstracting at the national and international levels in the field of Himalayan studies. ${ }^{9}$ Considering the importance of HIMIS, the government of India, through the agency of the National Information

\author{
Agricultural Information System \\ Ahamdabad Library Network \\ Biodiversity Conservation Information \\ System \\ Calcutta Library Network \\ Developing Library Network \\ Education Information System \\ Environmental Information System \\ Industrial Information System \\ Information and Library Network
}

Management Library Network

Medical Information System

Mysore Library Network

National Information System for Science and Technology

Nutrition Information System

Patent Information System

Project Information System

Pune Library Network

Rural Information System
Systems in Science and Technology (NISSAT), should aid and support the proposed HIMIS generously.

HIMIS is eminently suitable for several spheres of national activities, including planning and research. Reliable and timely information for decisionmaking becomes increasingly important for India, where a concept of social welfare has developed over the past three decades. Many organizations have successfully developed their own information systems to plan, monitor, or control their research activities, and these have yielded increased research proficiency. The government should surely benefit from these methods. Apart from suggesting suitable solutions to the problems of planning, monitoring, allocation, control, and coordination of the departmental programs, one has to consider the special distribution of these programs. ${ }^{10}$ The need to set up HIMIS has, therefore, to be considered in the context of the rapid development of Himalayan information as well as the increasing awareness of its relevance to societal development. ${ }^{11}$

\section{Objectives of HIMIS}

HIMIS will be fully computerized so that an efficient system of storage and retrieval could be organized through networks linking all the Himalayanstudies centers with each other. The main objectives of the proposed HIMIS are listed in appendix A.

\section{Users of the Proposed System}

The proposed information system is planned to meet the needs of the specialists who are directly or indirectly concerned with Himalayan studies and research as a subject or as an activity. The following are the categories of those to whom the information would be supplied in a meaningful form within a reasonable time through HIMIS.

1. planners, policy makers, decision makers, administrators with respect to Himalayan development at government and nongovernment levels;

2. major institutions devoted to Himalayan study and research as a discipline;

3. international organizations such as the United Nations Educational, Scientific, and Cultural Organization (UNESCO) and the International Centre for Integrated Mountain Development (ICIMOD); 
4. scientists engaged in the implementation and execution of plans and policies;

5. scientists and researchers engaged in Himalayan study and research;

6. teachers engaged in teaching about the Himalayas;

7. communicators who attempt to convey the information about development policies, plans, programs, and projects; and

8. NGOs working on projects about Himalayas.

\section{Components of the Proposed HIMIS}

For designing HIMIS, six essential components have been identified and proposed: (1) National Resource Center on Himalayan Studies; (2) library consortia; (3) computerization of Himalayan institutes' libraries; (4) information networking between Himalayan institutes; (5) digitization of information material on Himalayas; and (6) Himalayan information gateway. Figure 2 depicts the proposed components.

\section{National Resource Center on Himalayan Studies}

As a part of the information system, a national-level resource center for Himalayan studies is also proposed on the pattern of other information centers in India, such as the National Information Center for Management Information (NICMAN), Ahmedabad, and the National Information Center for Food Science and Technology (NICFOS), Mysore, to name but two. These information centers have been established with the financial help of NISSAT, and at present are working as sectoral information centers of NISSAT. Figure 3 describes various functions and activities of the proposed center. The planned objectives of the resource center are:
- to create a user-need-based information-technology (IT) resource center;

- to develop a strong collection of different types of information sources;

- to develop a user-friendly information-retrieval mechanism, such as an online facility for having access to international databases;

- to create an IT-based infrastructure;

- to develop a liaison with all Himalayan studies and research centers of India and other international centers for better information service through resource sharing and networking; and

- to provide bibliographies on selected topics on demand or even in advance of demand.

\section{Himalayan-Studies Libraries Consortium}

The concept of library consortia has been floating around for quite some time in India. Though it is the need of the hour, Indian libraries have yet to move in a definite direction in this regard. Strong resource-sharing activity among libraries, a prerequisite for the right attitude towards consortia activities, has not been as present in India as could be desired. Sudden influx of electronic information is forcing library consortia to materialize. ${ }^{13}$ Traditionally, the primary purpose of establishing a library consortium is to share physical resources amongst members. Access to resources is now considered more important than collection building, especially if the access is perpetual in nature. A library consortium helps libraries to get the benefit of wider access to electronic resources at an affordable cost and at the best terms of license.

A consortium with the collective strength of resources of the various institutions available to it is in a better position to address and resolve the problems of managing, organizing, and archiving electronic resources. ${ }^{14}$
The Indian National Digital Library in Science and Technology (INDEST) Consortium, which is set up by India's Ministry of Human Resource and Development, and UGC-Infonet, which is set up by the University Grant Commission of India are the best example of library consortia in India. Therefore, it is also proposed that a consortium of Himalayan institute's libraries may be formed to share the electronic resources of other libraries.

\section{Computerization of Himalayan-Studies Institute's Libraries}

Observance of an adherence to standard techniques, procedures, and methods is an essential prerequisite for the effective functioning of a network. Participating libraries will have to follow certain procedures and practices, without which the resources held by them cannot be effectively and meaningfully shared. In the context of library computerization, standardization is very necessary in such areas as classification, subject heading, and cataloging of various types of library materials; bibliographic description; and standard interchange of bibliographic data. ${ }^{15}$

The Himalayan institutes have started the computerization of their libraries, beginning with creation of computerized databases of books, journals, reports, conference proceedings, annual reports, and monographs. But not all the housekeeping activities have been computerized. It is, therefore, suggested that every library should begin the computerization of each and every one of their activities. In India, libraries are generally using Dewey Decimal Classification (DDC) for classification, Anglo-American Cataloguing Rules (AACR) for cataloging rules, and Library of Congress (LC) for subject headings. Machine-Readable Cataloging (MARC) fomat is being used in the majority of libraries for creation of the database. 


\section{Himalayan Institute's Network}

It is also proposed that there is a need for networking among the Himalayan Institute's libraries and information centers in the country for optimum resource sharing. Resource sharing and networking in libraries are powerful tools both for increasing productivity and enhancing services to meet the changing needs of library users. The proposed network ensures effective bibliographic control, document delivery, cooperative acquisition of serials and other literature in the field, and dissemination of relevant information. All the libraries and information centers of Himalayan-studies centers of India (see appendix B) will be linked to the National Resource Center on Himalayan Stud-ies. These libraries have been identified as regional centers of the proposed HIMIS. A network, in the first instance, envisaged a physical structure of links among the libraries and information centers established by means of computer and telecommunication links. Resource sharing is based on the concept that the collective strength and effectiveness of a group of libraries is greater than that of the sum of its individual members.

\section{Digitization of Himalayan- Information Sources}

Research publications are vital for any professional discipline, and it is crucial to preserve and provide access to them. Due to the amount of important information published in journals, conference proceedings, and reports, these efforts must be on a par with similar initiatives in other countries. Permanent preservation and enhanced access must be ensured vigorously now by the applications of new technology for digitizing and electronic access to valuable contents.

Digitization provides unhindered access to information via computer and communication networks, justi-

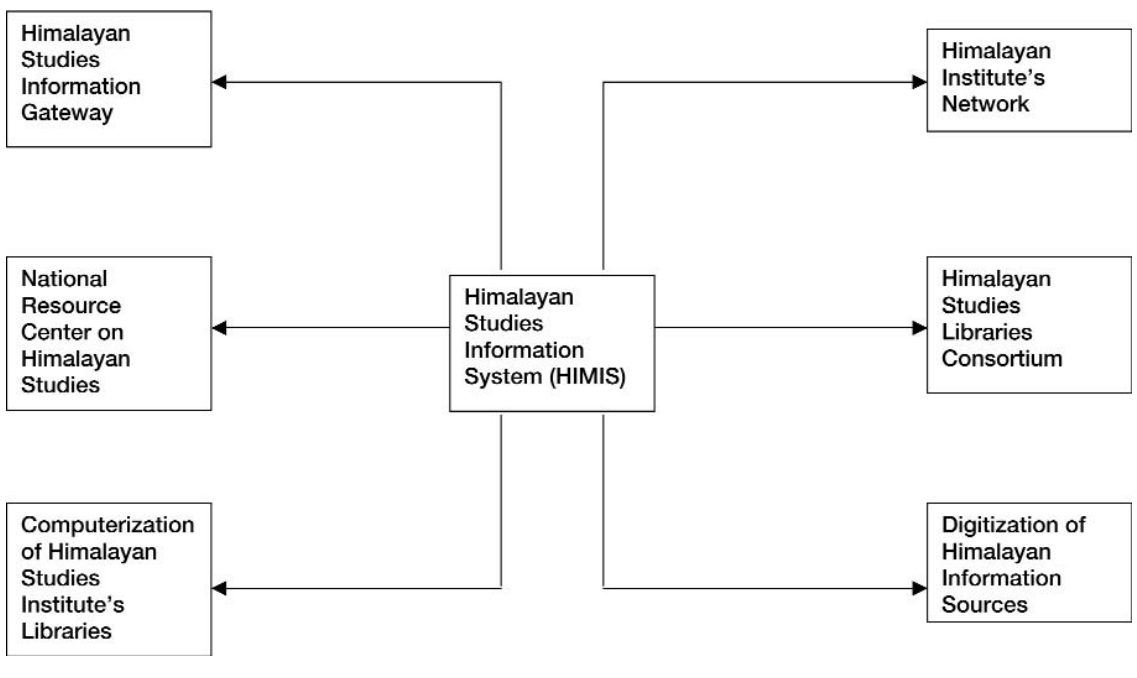

Figure 2. Components of HIMIS

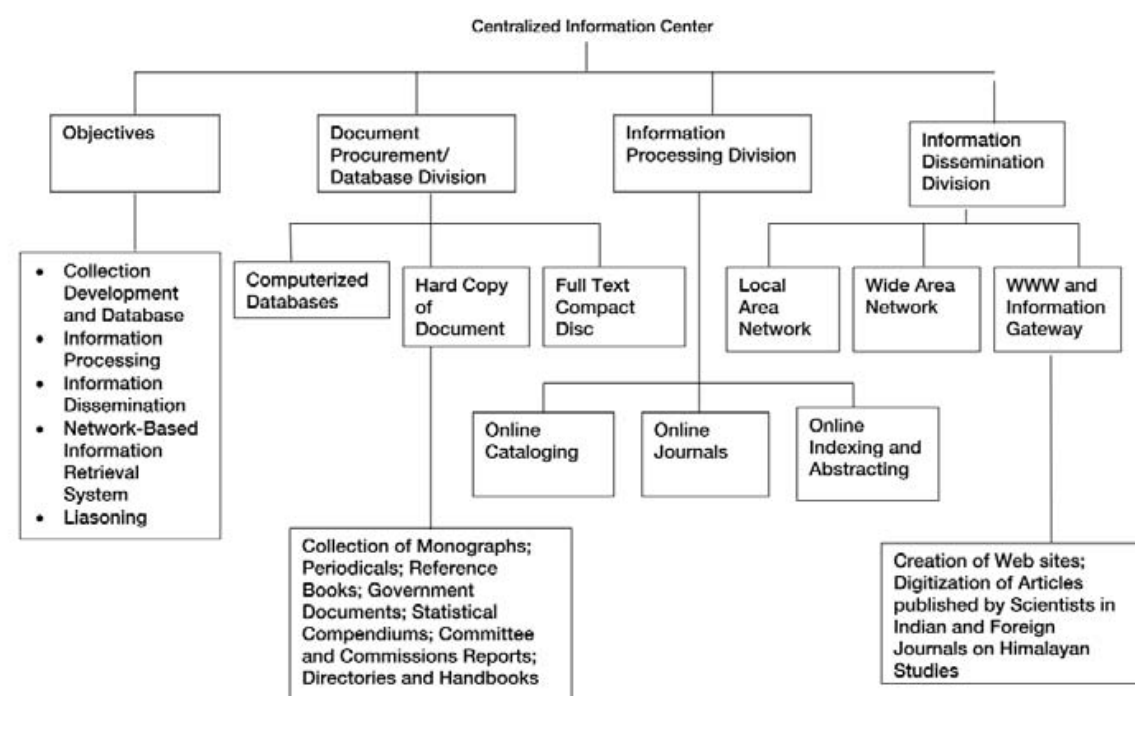

Figure 3. National Resources Center on Himalayan Studies in India

fying the need for using it for studying Himalayan literature. At present, very few copies of conference volumes, journals, and reports are published, and these are exclusively distributed to subscribers. The institutions involved rarely encourage readers to subscribe personally to such literature, thus placing it out of the reach of a large number of readers. The paper used for publishing these types of sources is of inferior quality, significantly reducing shelf life. In addition to providing increased and easy access to these publications, the most visible benefit of digitization is the fact that it preserves them. ${ }^{16}$ Some of the purposes 
ADINET (www.alibnet.org/)

AGRIS (www.fao.org/agris/)

CALIBNET (www.calibnet.org.in/)

CSIR (www.csir.res.in)

DELNET (www.delnet.nic.in/)

DESIDOC (http://drdo.nic.in/labindex. shtml)

DRDO (http://drdo.nic.in)

DST (www.dst.gov.in/)

ENVIS (http://envis.nic.in/)

HELLIS (www.hellis.org/)

ICAR (www.icar.org.in)

ICFRE (www.icfre.org)

ICSSR (www.icssr.org)

INDEST (http://paniit.iitd.ac.in/indest/)

INFLIBNET (www.inflibnet.ac.in)

Figure 4. URLs of Organizations, Networks, and Systems of India

of digitization, identified by different ongoing projects, are to:

- collect, store, and organize information and knowledge in digital form;

- promote economic and efficient delivery of information;

- leverage considerable investments in computing and communication infrastructures;

- strengthen communication and collaboration between research, government, and educational communities; and

- contribute for lifelong learning opportunities.

Keeping all of these points in mind, the digitization of Himalayan literature-particularly back volumes of journals, conference proceedings, annual reports, monographs, reports, and research papers published by Himalayan scientists in various journals, available in Himalayan studies centers of India-is very necessary. And it is one of the important and necessary aspects of the proposed HIMIS.
MoEF (www.envfor.nic.in)

MYLIBNET (www.mylibnet.org/)

NASSDOC (www.icssr.org/doc_mail.htm)

NICCHEM (www.dsir.nic.in/division/ nissat/nisnat/nics/mh.html)

NICFOS (www.cftri.com/department/ fostis.htm)

NICLAI (www.clri.org/)

NICMAN (www.iimahd.ernet.in/library/)

NISCAIR (www.niscair.res.in)

NISSAT (www.dsir.nic.in/division/nissat/)

PUNENET (www.punenet.com/)

UGC (www.ugc.ac.in)

UGC-Infonet

(http://web.inflibnet.ac.in/info/

ugcinfonet/ugcinfonet.jsp)
Internet, particularly in the field of Himalayan resources. As a result, it has become difficult for an individual-and also for an organizationto collect data and information. Thus, access to the right information at the right time has become very difficult. ${ }^{19}$

Since most of the information related to the Himalayas is scattered on the Web, it is necessary to develop a Himalayan-information subject gateway. This gateway will provide links to various libraries and information centers of R\&D institutions, universities, and NGOs working in the Himalayan region. This gateway will be developed on the pattern of the Sayama Prasad Mookerjee Information Gateway of Social Science (SPMIGSS) developed by the Indian Council of Social Science Research (ICSSR). ${ }^{20}$ The system, therefore, has to take into account the specific information requirements of each development sector insofar as its relevance to the Himalayas is concerned.

\section{Institutions Engaged in Himalayan Studies and Research}

One of the major problems in accessing information from the Internet is that it is very difficult and time consuming to get reliable and relevant information in the shortest possible time. The effective and efficient way to provide easy access to quality information on the Internet is developing Subject Gateways in specific areas. "Subject gateways are online services and sites that provide searchable and browseable catalogues of Internetbased resources. Subject gateways will typically focus on a related set of academic subject areas." ${ }^{\prime 17}$

To meet the information requirements of the scientific and academic communities in the digital era, various departments in India have developed or are still in the process of developing subject gateways in their respective areas. ${ }^{18}$ In recent years, there has been a tremendous explosion of data and information on the
To reduce the quantum of information illiteracy, it is essential that information is readily available to an individual about the agencies that generate and publish Himalayan information-a huge task. The main hurdle has been the lack of appreciation of the role and importance of this type of institutional activity on a continuing basis. Bearing in mind the concern for setting up HIMIS, the first step is to identify the agencies and institutions that generate Himalayan information. The information generated by these institutions may be contained in the form of files, computerized databases, reports, institutional publications, dissertations and theses, articles in journals, and conference and seminar papers. The information also is accumulated through state-of-the-art reports, serials, and yearbooks. ${ }^{21}$ India 
has a reasonably good institutional setup for Himalayan research. Figure 5 lists agencies currently involved in diverse fields of $R \& D$ on the Himalayas. Appendix B lists some of the institutions that are engaged in Himalayan studies and research. ${ }^{22}$

\section{Conclusion}

All Himalayan studies and research centers have to assume the major responsibility for developing HIMIS. The government of India needs to be convinced of the usefulness and utility of such a system. It is necessary to emphasize that in the absence of such an information system, a large amount of research talent and resources will be wasted in duplicated efforts. It is hoped that the Himalayan institutions and scientists engaged in Himalayan studies and research will be able to impress upon the government of India the need for an early formulation and implementation of HIMIS. ${ }^{23}$ This information system will also supplement the resources and services of the participating libraries as "libraries acting together can more effectively satisfy user needs and thus meet the objectives at reduced costs." The success of the venture shall depend upon financial support, guidance, and encouragement received from government of India. ${ }^{24}$

\section{References}

1. R. L. Raina, and I. V. Malhan, eds., Business Librarianship and Information Services: Proceedings of the IIML-MANLIBNET 3rd Annual National Convention, March 12-14, 2001, Lucknow: (Lucknow: International Book Distributing Co., 2002), v-vii.

2. Shekhar Pathak and Anup Sah, Kumaon Himalaya, Temptations (Nainital: Published for Kumaon Mandal Vikas Nigam Ltd. by Gyanodaya Prakashan, 1993).

3. N. K. Shah, S. D. Bhatt, and R. K. Pande, Himalaya: Environment Resources and Development (Almora: Shree Almora Book Depot, 1990), iii.

Council of Scientific and Industrial Research (CSIR)

Defence Research and Development Organization (DRDO)

Department of Science and Technology (DST)

Indian Council of Agricultural Research (ICAR)

Indian Council of Forests Research and Education (ICFRE)

Ministry of Environment and Forests (MoEF)

Nongovernmental Organizations (NGOs)

Universities Centers under the network of University Grant Commission (UGC)

Science, Technology, and Environment departments in various Himalayan States

Figure 5. Agencies Involved in Himalayan Research

4. P. C. Bose, "National Agricultural Research Information System," in National Information Policies and Programmes, Seminar Papers Thirty-Seventh All-India Library Conference, (Delhi: Indian Library Association, 1991), 177.

5. D. E. Avinson and G. Fitzgerald, Information Systems Development: Methodologies, Techniques and Tools (Oxford: Blackwell Scientific, 1988), 7.

6. Ibid., 8 .

7. Raymond Prytherch and L. M. Harrod, Harrod's Librarians' Glossary of Terms Used in Librarianship, Documentation, and the Book Crafts, and Reference Book, 6th ed., (Aldershot, U.K.: Gower Pub., 1987), 385.

8. C. M. Bowman, "The Development of Chemical Information Systems," in Chemical Information Systems, J. E. Ash, and Ernest Hyde, eds. (Chichester, U.K.: Ellis Horwood, 1975), 6.

9. N. K. Goil, "Need for a Social Science Information System: Guidelines for a Model for India," Library Herald 17, nos. 1-4 (1975-1979): 81.

10. S. P. Agrawal, "National Information System in Social Sciences in India: A Review," in Twenty-Eighth All-India Library Conference, October 20-23, 1982, Lucknow: Seminar Papers of Planning for National Information System, J. L. Sardana et al., eds. (Delhi: Indian Library Association, 1982), 273-74.

11. S. P. Agrawal, "National Information System in Social Sciences," in Handbook of Libraries, Archives and Information Centers in India, vol. 3, Information Policy Systems and Networks, B. M. Gupta et al., eds. (New Delhi: Information Industry Pub., 1986), 183.

12. Raina, Roshan, "National Information System for Geoscience in India," in
Twenty-Eighth All-India Library Conference, October 20-23, 1982, Lucknow: Seminar Papers of Planning for National Information System, J. L. Sardana et al., eds. (Delhi: Indian Library Association, 1982), 262-63.

13. Swati Bhattacharyya, "Library Consortia: Towards an Action Plan," in Business Librarianship and Information Services: Proceedings of the IIML-MANLIBNET 3rd Annual National Convention, March 12-14, 2001, Lucknow, R. L. Raina and I. V. Malhan, eds. (Lucknow: International Book Distributing Co., 2002), v-vii.

14. Jagdish Arora and Pawan Agrawal, "Indian National Digital Library in Science and Technology (INDEST) Consortium: Consortium-Based Subscription to Electronic Resources for Technical Education System in India," in Mapping Technology on Libraries and People: proceedings of the Second International Conference Automation of Libraries in Education and Research Institutions (Ahmedabad: INFLIBNET, 2003), 272-73.

15. Hanif Uddin, Md. and Haru-orRashid, Md. (2002), "Networking of Agricultural Information Systems in Bangladesh (BD-AGRINET): A Model," Library Herald 40, no. 1 (2002): 11.

16. V. K. J. Jeevan, "Digitizing of Indian Library Science Journals," University News 39, no. 34 (2001): 5-13.

17. DESIRE Subject Gateways. Accessed July 30, 2003, www.desire.org/ html/subjectgateways/community / imesh/.

18. Anil Singh and J. N. Gautam, "Himalayan Information Subject Gateway in Digital Era: A Proposal for Its Development," DESIDOC Bulletin of Information Technology 23, no. 2 (Mar. 2003): 3-9. 
19. P. C. Bose, "National Agricultural Research Information System," 177.

20. ICSSR Newsletter 23, no. 4 (Jan.-Mar. 2002): 24.

21. Goil, "Need for a Social Science Information System," 72-73.

22. P. Pushpangadan and K. Narayanan
Nair, "Future of Systematics and Biodiversity Research in India: Need for a National Consortium and National Agenda for Systematic Biology Research," Current Science 80, no. 5 (2002): 633.

23. N. K. Goil, "Need for a Social Science Information System," 92.
24. Amritpal Kuar, "Networking of the Libraries of Agricultural Universities and Research Institutes in the States of Punjab, Haryana, and Himachal Pradesh (PHHALNET): A Proposal," Library Herald 33, nos. 3-4 (1995-1996): 113.

\section{Appendix A. Main Objectives of HIMIS}

The main objectives of the proposed HIMIS are as follows:

- to identify, study, and survey the existing Himalayan information infrastructure in the country;

- to function as an information base so that policy makers, administrators, and scientists can access the computerbased information in special fields and build up their expertise;

- to function as a computer-based information storage-and-retrieval system database that collects structured information generated by research institutions, continuously updating and making the information available to users

- to provide a communications link with international databanks and databases for selective bibliographic information to scientists and other users;

- to examine, promote, and develop existing information services and resources to meet the information requirements of scientists working in the area of Himalayan research;

- to establish and maintain links with other national information centers and systems in the country; ${ }^{12}$

- to create a linked collection of Internet-based, high-quality Himalayan resources;

- to convert core Indian Himalayan journals, research reports, dissertations, and working papers into digital format;

- to keep Indian databases of Himalayan journals and newsletters of Himalayan Institute's online;

- to establishing a network of all Himalayan-studies research centers situated in different parts of the country for sharing research resources;

- to provide online information of forthcoming conferences, seminars, and training workshops in Himalayan-researchand-studies centers in India;

- to provide details of completed and on-going Himalayan-research projects;

- to connect Web sites of Himalayan studies, hill studies departments of major universities, and Himalayan-research institutes;

- to provide for discussions, chat groups, and video-conferencing facilities for Himalayan scientists;

- to share the resources of other libraries to supplement a library's own collection;

- to share scientific efforts and expertise;

- to ensure effective bibliographic control of the literature;

- to facilitate and promote document-delivery and library-lending services;

- to develop a common collection-development policy;

- to share catalog service and to create a computerized union database;

- to share database services such as abstracting, indexing, and full-text services;

- to collect, store, organize, and retrieve information on all aspects of Himalaya and its interdisciplinary areas contained in various recorded media; and

- to coordinate the existing resources, services, and facilities within India in the field of Himalayan studies.

\section{Appendix B. Institutions Engaged in Himalayan Research}

\section{Universities}

Center for Environmental Sciences, Himachal Pradesh University, Shimla (http://hpuniv.nic.in/envstu.htm)

Center for Himalayan Studies, University of North Bengal, Darjeeling (www.nbu.ac.in/)

Center for Interdisciplinary Studies of Mountain and Hill Environment, University of Delhi, Delhi

G. B. Pant University of Agriculture and Technology, Ranichauri, Tehri-Garhwal (www.gbpuat.ac.in/) 
North East Hill University, Shillong (www.nehu.ac.in/)

High Altitude Plant Physiology Research Center, H. N. B. Garhwal University, Srinagar-Garhwal

Dr. Y. S. Parmar University of Horticulture and Forestry, Solan (www.yspuniversity.ac.in/)

Institute of Integrated Himalayan Studies (IIHS), (UGC Center of Excellence)

Himachal Pradesh University, Shimla (www.hpuniv.nic.in/)

Institute of Himalayan Studies and Regional Development, Garhwal University, Srinagar-Garhwal

\section{R\&D Institutions}

Central Institute of Higher Tibetan Studies, Sarnath, Varanasi (www.smith.edu/cihts/)

Central Institute of Himalayan Culture Studies, Dahung, Arunachal Pradesh

Defence Agricultural Research Laboratory (DRDO) Pithoragarh (http://drdo.nic.in/labindex.shtml)

Snow and Avalanche Study Establishment, (DRDO) Chandigarh (http://drdo.nic.in/labindex.shtml)

Temperate Forest Research Institute (ICFRE), Shimla (www.envfor.nic.in/icfre/tfris/tfris.html)

Himalayan Forest Research Institute, Shimla (www.icfre.org/institues/hfri.htm)

Forest Research Institute (ICFRE), Dehradun (www.envfor.nic.in/icfre/fri/fri.html)

Institute of Himalayan Bioresources Technology, (CSIR) Palampur (www.csir.res.in/ihbt/)

Regional Research Laboratory, (CSIR) Jammu Tawi (www.rrljammu.org/)

G. B. Pant Institute of Himalayan Environment and Development, with its headquarters at Almora; and regional units at

Tadong-Gangtok; Srinagar-Garhwal; Shamshi-Kullu; Itanagar (http://gbpihed.nic.in/)

ICAR Research Complex for NEH Region, (ICAR) Umroi Road : Barapani, Meghalaya (http://dare.nic.in/icarneh.htm)

Vivekananda Parvatiya Krishi Anushandhanshala (ICAR), Almora (http://vpkas.nic.in/)

Central Institute of Temperate Horticulture (ICAR), Srinagar, Jammu and Kashmir (http://dare.nic.in/cith.htm)

Indian Veterinary Research Institute, Regional Station, Palampur (ICAR) (http://ivri.nic.in/)

Indian Veterinary Research Institute, Regional Station, Muketeswar (ICAR), Nainital (http://ivri.nic.in/)

National Bureau of Plant Genetic Resources, Regional Station, Bhowali-Niglat, Nainital (http://nbpgr.delhi.nic.in/)

North Eastern Regional Institute of Science and Technology, Nirjuli, Itanagar (http://agni.nerist.ac.in/)

Wadia Institute of Himalayan Geology, (DST) Dehradun (www.himgeology.com/)

Wildlife Institute of India, Dehradun (www.wii.gov.in/)

\section{International Center}

International Center for Integrated Mountain Development (ICIMOD), Kathmandu, Nepal (www.icimod.org/)

\section{NGOs}

Center of Himalayan Development and Policy Studies, Dehradun

Himalayan Environmental Studies and Conservation Organization, Kotdwara (Garhwal), Uttaranchal

Society for Integrated Development of Himalayas (SIDH), Landour Cantt., Musoorie

Himalayan Action Research Center (HARC), Dehradun

Himalayan Study Circle, Pithoragarh

People's Association for Himalayan Area Research (PAHAR), Nainital

The Himalaya Trust, Dehradun

The Himalayan Foundation, Nandprayag, Chamoli Distt

Research, Advocacy, and Communication in Himalayan Areas (RACHNA), Dehradun

Central Himalayan Environment Association, Nainital

Himalayan Region Study and Research Center Institute, New Delhi

Himalayan Seva Sangh, New Delhi

Himalayan Research Group, Nainital

Himalayan Research and Cultural Foundation, New Delhi

Himalayan Institute of Action Research and Development, Dehradun 